Article

\title{
Intersection Control and Delay Optimization for Autonomous Vehicles Flows Only as Well as Mixed Flows with Ordinary Vehicles
}

\author{
Abdullah Baz * ${ }^{\mathbb{D}}$, Ping Yi $\mathbb{D}^{\mathbb{D}}$ and Ahmad Qurashi \\ Department of Civil Engineering, The University of Akron, Akron, OH 44325, USA; pyi@uakron.edu (P.Y.); \\ aaq1@zips.uakron.edu (A.Q.) \\ * Correspondence: aab121@zips.uakron.edu
}

Received: 28 July 2020; Accepted: 24 August 2020; Published: 26 August 2020

check for updates

\begin{abstract}
The rapidly improving autonomous vehicle (AV) technology will have a significant impact on traffic safety and efficiency. This study introduces a game-theory-based priority control algorithm for autonomous vehicles to improve intersection safety and efficiency with mixed traffic. By using vehicle-to-infrastructure (V2I) communications, this model allows an AV to exchange information with the roadside units (RSU) to support the decision making of whether an ordinary vehicle (OV) or an AV should pass the intersection first. The safety of vehicles is taken in different stages of decisions to assure collision-free intersection operations. Two different mathematical models have been developed, where model one is for an AV/AV situation and model two is when an AV meets an OV. A simulation model was developed to implement the algorithm and compare the performance of each model with the conventional traffic control at a four-legged signalized intersection and at a roundabout. Three levels of traffic volume and speed combinations were tested in the simulation. The results show significant reductions in delay for both cases; for case (I), AV/AV model, a 65\% reduction compared to a roundabout and $84 \%$ compared to a four-legged signalized intersection, and for case (II), AV/OV model, the reduction is $30 \%$ and $89 \%$, respectively.
\end{abstract}

Keywords: autonomous vehicles; intersection management; delay reduction; vehicle-to-infrastructure; ordinary vehicles; game theory; signalized intersection; roundabout

\section{Introduction}

Autonomous vehicles (AVs) are driverless vehicles that can communicate with other systems and make driving decisions for themselves [1]. Decisions made by AVs may range from car-following and speed control to lane change and route selection, and they make decisions through processing data from the onboard sensors or by receiving information from the infrastructure or other vehicles [2]. Traffic engineers are looking to take advantage of AVs to enhance traffic safety and improve operational efficiency. One way of taking advantage of AVs is by using them in intersections management [3].

Intersections are a vital area for resolving traffic conflict [4]. For decades we have used traffic signals to regulate traffic flow going through intersections according to designated signal cycles, phases and intervals. However, this method of intersection control has proven to be inefficient with capacity constraint, mainly because of the need to separate conflicting vehicle trajectories and adjust signal timing to accommodate the required reaction time of human drivers. In the context of autonomous vehicles, the conventional method of signal control for intersections may no longer be needed; in the meantime, the capacity and efficiency of intersections may be largely increased due to data communication capabilities and minimized reaction time of autonomous vehicles. In this paper, we have come up with a novel method for intersections management with AV flows. Under safety guidelines, we intend to improve traffic efficiency by reducing delays for the approaching vehicles. 
By using vehicle-to-infrastructure (V2I) and vehicle-to-vehicle (V2V) technology an approaching $\mathrm{AV}$ is able to share information with a roadside unit (RSU) so that its speed can be controlled to avoid conflict as it safely goes through the intersection $[5,6]$. Depending on the vehicle and field conditions, the decision process may need to take into consideration factors such as approaching speed, distance and relative position to other vehicles and turning movement and dimensions of each vehicle [7]. Since this decision process is similar to strategy generations in game theory, we have followed this method to build the payoff matrix for each different combination of factors. Two cases have been studied and simulated in this research, where case (I) is for a situation involving AV/AV in all directions and case (II) includes an AV on one road and an ordinary vehicle (OV) on the conflict road.

Most of the studies and research on AV intersection control focus on the $100 \%$ AV case. Zohdy, I.H., Kamalanathsharma, R.K. and Rakha, H. in [8] proposed a new tool to control vehicle trajectories using cooperative adaptive cruise control (CACC) systems to avoid collisions. They used an optimization model to minimize the waiting time if there is a conflict by dividing the intersection into three zones, in the first zone to get all AVs to their max speed, second zone for adjusting speed if needed and then go back to the maximum to pass the third zone. They applied the model to a four legged intersection with only one car in each direction. A reservation-based approach called (AIM) has been done by [9-11] - when the AV enters the controller coverage area, they send a request to enter the intersection then the controller will simulate the trajectory of the vehicle and if there is no conflict with any other vehicle then it will accept, otherwise it will cancel the request. Only few researchers have talked about the mixed traffic case, like Ahn and Colombo, who proposed a design of a supervisor that manages controlled vehicles or ordinary vehicles [12], their proposed method proven mathematically. However, this study was fully verified mathematically and then tested by a modeling simulation. The majority of autonomous vehicles research mainly concentrates on electrical, technological and machine learning concepts. The contribution of this study is to cover the subject from a traffic engineering background, where the variation of road capacity, traffic volume and vehicle speed plays a major rule in validation of any intersection management approach.

This study deals with intersections as they are crucial nodes in the transportation network, where vehicles approaching the same area from different directions cause a lot of conflicts. That reduces the capacity of the roads, increases traffic delay and reduces the safety on roads. According to [13], delays at road intersections account for more than $80 \%$ of the total road network delays, and $40 \%$ of traffic accidents happen in an intersection [14]. There are different types of intersection management methods, each type has its own characteristics, parameters, advantages and disadvantages. In this paper, we compared the analytical results of our proposed intersection management method with the results of the two most widespread and efficient methods: signalized intersections and roundabouts. A roundabout is a perfect method for low traffic density [15], they have less conflict points than a signalized intersection [16], whereas a signalized intersection can handle high traffic flow better, but the effect of a signalized intersection on traffic delay is particularly obvious where vehicles are forced to a complete stop [17].

This paper includes five sections to describe the algorithm development and testing. The last section summarizes the positive results of the study on intersection improvement when it is compared with other methods of intersection control.

\section{Game Theory}

Game theory is a branch of mathematics concerned with the analysis of strategies for decision-making where outcomes depend upon choices made by one or more players [18]. In other words, the game theory is used to find the best solution when the decision one is trying to make depends on the other party's choice. Game theory has been applied in many fields, for instance, economy, war, business, biology and many others [19].

There are different types of games and each type has its own mathematical solution method for the problems. For instance, in a cooperative game, players are allowed to negotiate and reach an 
agreement, but in a noncooperative game, collaboration is not applicable [20]. In addition, there are simultaneous and sequential move games, zero-sum (the sum of outcomes of all the players is zero) and non-zero-sum games [21], etc. In the case of intersection application, our problem can be classified as a cooperative, a sequential move and a non-zero-sum game [22-24].

Assume a two-player game, where

Player A has a finite strategy set $S=\{s 1, \mathrm{~s} 2, \ldots, \mathrm{sm}\}$

Player B has a finite strategy set $T=\{t 1, t 2, \ldots, t n\}$

When the pair of strategies $(\mathrm{si}, \mathrm{tj})$ is chosen, the payoff to the first player and second player is aij = $\mathrm{uA}(\mathrm{si}, \mathrm{t} \mathrm{j})$ and $\mathrm{bij}=\mathrm{uB}(\mathrm{si}, \mathrm{tj})$, respectively. $\mathrm{uA}, \mathrm{uB}$ are payoff functions. The values of payoff functions can be formed separately for different players:

$$
\mathrm{A}=\left[\begin{array}{ccc}
a_{11} & \ldots & a_{1 n} \\
\ldots & \ldots & \ldots \\
a_{m 1} & \ldots & a_{m n}
\end{array}\right] \mathrm{B}=\left[\begin{array}{ccc}
b_{11} & \ldots & b_{1 n} \\
\ldots & \ldots & \ldots \\
b_{m 1} & \ldots & b_{m n}
\end{array}\right]
$$

Matrix A or B in Equation (1) is called a payoff matrix. Together, the two matrices can form a bimatrix, Equation (2), that shows different decision combinations and the subsequent outcomes.

\begin{tabular}{|c|c|c|c|c|c|}
\hline & \multicolumn{5}{|c|}{ Player 2} \\
\hline \multirow{4}{*}{ Player 1} & Strategy & $t_{1}$ & $t_{2}$ & $\ldots$ & $t_{n}$ \\
\hline & $S_{1}$ & $\left(a_{11}, b_{11}\right)$ & $\left(a_{12}, b_{12}\right)$ & $\ldots$ & $\left(a_{1 n}, b_{1 n}\right)$ \\
\hline & $S_{2}$ & $\left(a_{21}, b_{21}\right)$ & $\left(a_{22}, b_{22}\right)$ & $\ldots$ & $\left(a_{2 n}, b_{2 n}\right)$ \\
\hline & $\begin{array}{l}\vdots \\
S_{m}\end{array}$ & $\left(a_{m 1}, b_{m 1}\right)$ & $\left(a_{m 2}, b_{m 2}\right)$ & $\ldots$ & $\left(a_{m n}, b_{m n}\right)$ \\
\hline
\end{tabular}

In the case of intersection control, players are the vehicles, where each vehicle has three possible trajectories to follow-going through, turning right or turning left when approaching the intersection. Depending on a vehicle's routing choice, its speed and distance from the intersection, a conflict point between two or more vehicles can be calculated [25]. In the context of autonomous vehicles, conventional traffic signals are not used. Thus, a real-time decision making will take place for each vehicle to ensure safety and reduce delay. Priority must be set for each vehicle to either speed up, cruise or slow down (stop). The smaller the decision outcome value in the payoff matrix, the less the delay. A zero-outcome value means there is no delay for that particular vehicle [26].

Autonomous vehicles can exchange information with each other and with the roadside unit, which makes it a cooperative game [27] with the objective of minimizing delay. Moreover, it is also a sequential move game because if one vehicle makes a decision then the other(s) must respond accordingly. On the other hand, in mixed traffic with ordinary vehicles the priority is given to OVs; thus, the decision process is more complex, as explained in the following sections.

\section{Development of a Priority Control Algorithm}

\subsection{Case Study (I) AV/AV Vehicles in All Directions}

This model considers a four-legged intersection as shown in Figure 1. For the purpose of algorithm development, we assume only one lane in each direction and that vehicles' arrivals are from the southbound and eastbound approaches. 


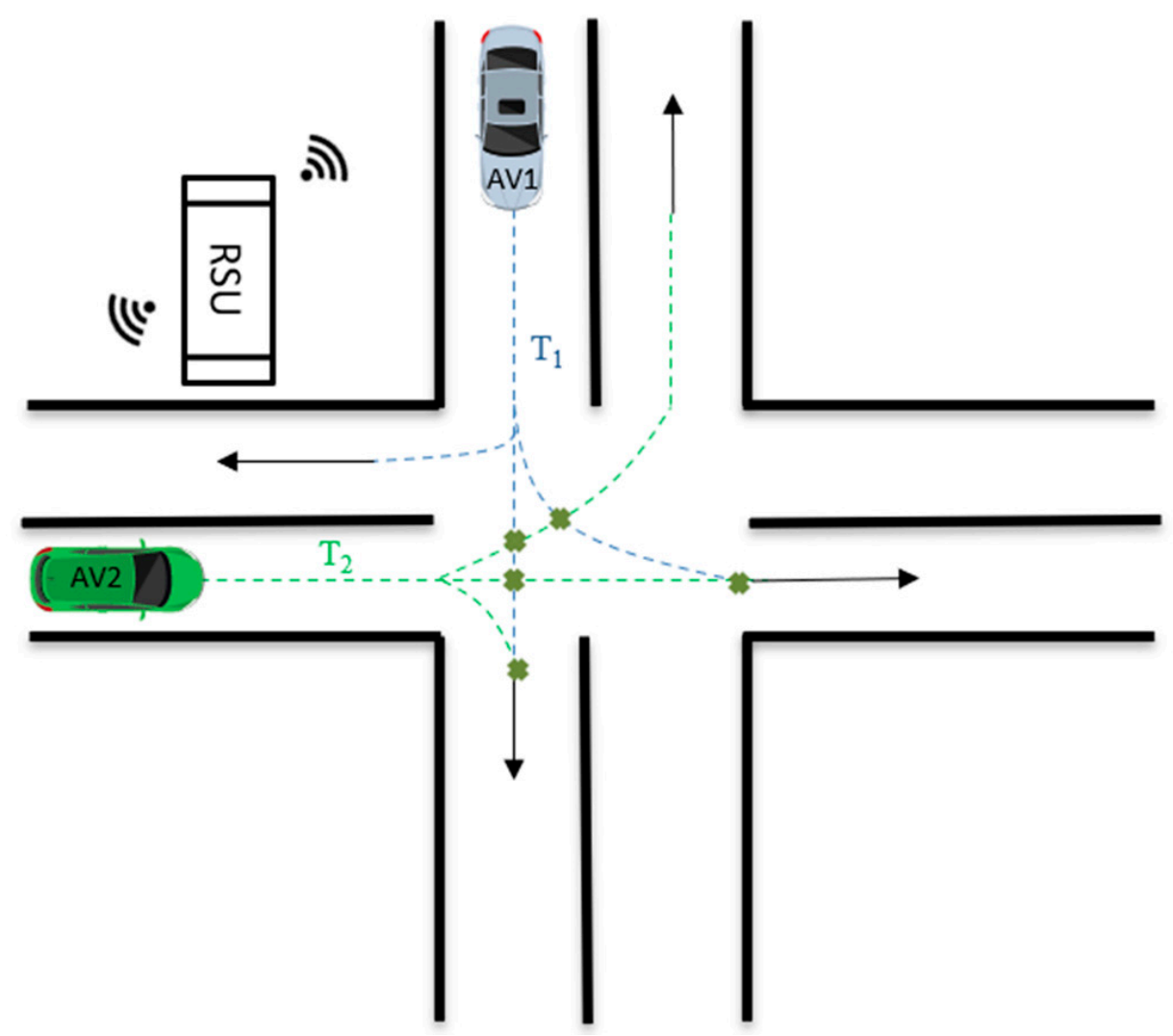

Figure 1. Case (I) AV/AV vehicles in both directions. AV, autonomous vehicle, RSU, roadside units. where,

$\mathrm{AV}_{1}$ : autonomous vehicle on southbound.

$\mathrm{AV}_{2}$ : autonomous vehicle on eastbound.

$\mathrm{D}_{1}$ : distance from $\mathrm{AV}_{1}$ to the conflict point with $\mathrm{AV}_{2}$.

$\mathrm{D}_{2}$ : distance from $\mathrm{AV}_{2}$ to the conflict point with $A V_{1}$.

$T_{1}$ : time needed for $A V_{1}$ to reach the conflict point with $A V_{2} \cdot T_{1}=D_{1} / v_{1}$

$T_{2}$ : time needed for $A V_{2}$ to reach the conflict point with $A V_{1} \cdot T_{2}=D_{2} / v_{2}$

$\mathrm{v}_{1}$ : speed of $\mathrm{AV}_{1}$.

$\mathrm{v}_{2}$ : speed of $\mathrm{AV}_{2}$.

The intersection is assumed to be equipped with an RSU that allows V2I communication. When an AV enters the communication range, it is connected to the RSU to share its data such as speed, direction, location and vehicle type and dimensions [28]. The control system analyzes the received data from all approaching vehicles to determine if there co-exists a spatial and temporal conflict between vehicle trajectories and then prioritize the movements of the vehicles.

\subsubsection{Conflict Point}

In this model, there are five possible conflict points between any two vehicle trajectories going to different directions as shown in Figure 1. The conflict point is in fact an area in which vehicles may collide, and it is the length of one vehicle plus the width of the other one [29] as shown in Figure 2. In other words, to avoid conflict, one vehicle has to slow down or speed up to separate from the other vehicle by at least $(w+1)$. This distance can be converted to time when vehicle speed is known [30].

In general, priority is given to the vehicle coming to the intersection earlier than the other vehicle. However, if two vehicles arrive at the same time, the intersection control rule states that the one on 
the right side has the right of way to go first [31]. For example, in Figure 2 when both vehicles are expected to arrive at the conflict point at the same time, $A V_{1}$ traveling on the southbound has to yield to $\mathrm{AV}_{2}$ on its right, which is traveling east. It is likely that another eastbound vehicle may be following $\mathrm{AV}_{2}$ to the intersection, if so, the decision process continues recursively. In case repeated slowdowns are required for $A V_{1}$ due to consecutive eastbound vehicles, a preset maximum allowable number may be used to avoid excessive waiting for $\mathrm{AV}_{1}$. In the simulation and testing study presented later, we have preset this number to not exceed five and found that delay is not sensitive to this number under the given traffic demand.

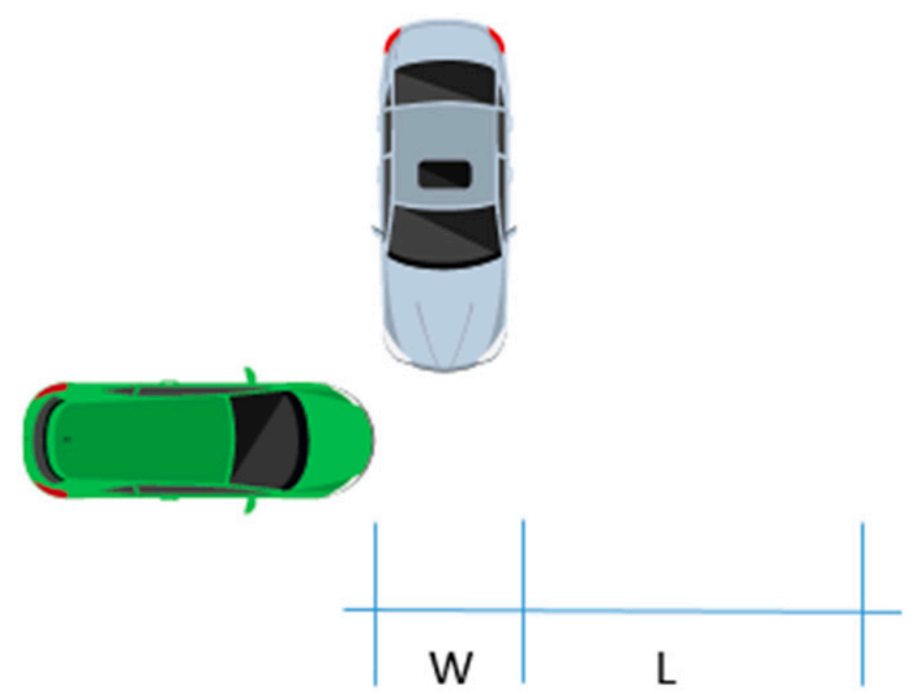

Figure 2. Illustration of the conflict point (area).

\subsubsection{Delay Time (DT)}

If a vehicle needs to slow down as a result of decision making, then delay is calculated. Since the arrival time of the vehicles to the conflict point should be separated by a safety margin, $\Delta t$, assume $A V_{1}$ has the priority to enter intersection the scale of the slowdown by $\mathrm{AV}_{2}$ will be the delay time (DT), as

$$
\mathrm{DT}=\mathrm{T}_{1}-\mathrm{T}_{2}+\Delta \mathrm{t}_{12}
$$

where, $T_{1}$ : time needed for $A V_{1}$ to reach the conflict point with $\mathrm{AV}_{2}$.

$T_{2}$ : time needed for $A V_{2}$ to reach the conflict point with $A V_{1}$.

$\Delta t_{12}$ : safety margin time that $A V_{2}$ have to provide for $A V_{1}$ to pass first.

In Equation (3), DT expression $\Delta \mathrm{t}_{12}$ should at least provide the minimum time gap for the rear bumper of the proceeding vehicle to exit the conflict point, before the front bumper of the delayed vehicle to enter the conflict point [32]. Although AVs do not need as much reaction time as human drivers require, it is still necessary to provide an adequate braking time for an $\mathrm{AV}$ to stop in case of emergency. Instances of emergency may include objects dropping to block the proceeding vehicle or, in the worst case, technical issues that have made the proceeding vehicles stop right at the conflict point. The delayed vehicle from the crossroad must react to the situation in order to avoid a collision. Thus, additional braking time (BT). Equation (4), [33] should be included in $\Delta \mathrm{t}_{12}$, as;

$$
\mathrm{BT}=\frac{\mathrm{v}_{2}}{2 \mathrm{~g}[\mathrm{f} \pm(\mathrm{G})]}
$$

where $\mathrm{f}$ is the friction coefficient, $\mathrm{G}$ is roadway grade, $\mathrm{g}$ is the gravity constant, and $\mathrm{V}$ is the approaching speed [34]. 
It is important to recognize that other factors may also affect the safe operation of AVs. Such factors may include delay in data communication with the RSU or the mechanical engagement time for braking, etc [35]. Those factors may change from one vehicle to another and from time to time, but in general, it is reported that the combined effect from them is round $0.03 \mathrm{~s}$ [36]. When all of above considerations are included, the final safety margin time $(\Delta t)$-for simplification the subscript is dropped so that $\Delta t$ represents either $\Delta \mathrm{t}_{12}$ or $\Delta \mathrm{t}_{21}$ as appropriate—can be written as in Equation (5);

$$
\Delta \mathrm{t}=\frac{\mathrm{w}+1}{\mathrm{v}_{1}}+\frac{\mathrm{v}_{2}}{2 \mathrm{~g}[\mathrm{f} \pm(G)]}+0.034
$$

where, $w$ is the width of $A V_{1}, l$ is the length of $A V_{2}, v_{1}$ is the speed of $A V_{1}, v_{2}$ is the speed of $A V_{2}$.

\subsubsection{Case (I) AV/AV Game Strategy for Intersection}

Considering two autonomous vehicles approaching the intersection at the same time, each AV has three possible choices: going through (GT), turning right (TR) or turning left (TL). Since there are five possible conflict points as shown in Figure 1, in each case one of the vehicles needs to slow down before it reaches the intersection, and by the time the vehicle comes to the conflict point, the other vehicle should have safely passed that point. The objective function is to reduce the waiting time (delay) for the vehicles thus to increase intersection efficiency. This can be done by initially classifying the combination of arrival times into different types of time zones by the vehicles when they enter the communication domain (the intersection) and approach the possible conflict point. The first type of time zone is when one AV can pass the conflict point before the other arrives without changing its speed; the second type is when this AV can cross the conflict point after the other has safely passed the point without changing its speed; the third type of time zone is in between the above two types, in which the trajectory conflict may exist at the same time, and one of the two vehicles needs to adjust its speed.

During the V2I communication, the following specific cases, to which we apply game theory, are possible:

- If $T_{1}<T_{2}-\Delta t, A V_{1}$ proceeds freely to pass the intersection before $\mathrm{AV}_{2}$ arrives at the conflict point. The DT for both $\mathrm{AV}_{1}$ and $\mathrm{AV}_{2}$ is zero.

- If $T_{2}-\Delta t<T_{1}<T_{2}+\Delta t$, conflicts are possible. $A V_{1}$ must yield the right-of-way to the vehicle on the right, $\mathrm{AV}_{2} . \mathrm{AV}_{1}$ adjusts its speed to avoid a collision. The $\mathrm{DT}$ for $\mathrm{AV}_{2}$ is zero and the delay time for $A V_{1}$ is $\left(T_{1}-T_{2}+\Delta t\right)$.

- If $T_{1}>T_{2}+\Delta t, A_{2}$ proceeds freely to pass the intersection before $A_{1}$ arrives at the conflict point. The DT for both vehicles is zero.

\subsubsection{Desired Speed for the Following Vehicles}

The decision-making algorithm will be applied recursively to any vehicle approaching the intersection. In case of conflict, the slowing down vehicle might affect the speed of the vehicle behind it, for that a speed reduction mechanism should be formulated to control the movement of those vehicles.

$T_{A V 1}$ : time needed for $A V_{1}$ to reach the conflict point.

$T_{A V 2}$ : time needed for $A_{2}$ to reach the conflict point.

$\Delta T_{A V 1}$ : time between $A V_{1}$ and $A V_{2}$.

$\Delta T_{A V 2}$ : time between $A V_{2}$ and $A V_{3}$.

To minimize the delay of $\mathrm{AV}_{2}$ illustrated in Figure 3, the system needs to check if the difference in time between the two successive $\mathrm{AVs}$ (i.e., $\Delta \mathrm{T}_{\mathrm{AV}}$ ) is greater than the delay time for $\mathrm{AV}_{1}$ plus the time $\left(\Delta \mathrm{t}_{1}\right)$ to cover the vehicle length. If this condition $\left(\Delta \mathrm{T}_{\mathrm{AV} 1}>\mathrm{DT}_{1}+\Delta \mathrm{t}_{1}\right)$ is met, then there is no need for 
$\mathrm{AV}_{2}$ to slow down; otherwise, $\mathrm{AV}_{2}$ has to slow down and the desired speed for $\mathrm{AV}_{2}$ can be calculated as in Equation (6):

$$
\mathrm{V}_{\mathrm{AV} 2}=\frac{\mathrm{D}_{2}}{\mathrm{~T}_{\mathrm{AV} 2}+\Delta \mathrm{T}_{\mathrm{AV} 1}+\Delta \mathrm{t}_{1}}
$$

where:

$\mathrm{T}_{\mathrm{AV} 2}=\mathrm{D}_{2} / \mathrm{V}_{2}$

$\mathrm{V}_{2}$; the speed of $\mathrm{AV}_{2}$ to the conflict point before changing speed.

$\mathrm{D}_{2}$; the speed of $A V_{2}$ to the conflict point before changing speed.

$\Delta \mathrm{T}_{\mathrm{AV} 1}=\mathrm{T}_{\mathrm{AV} 2}-\mathrm{T}_{\mathrm{AV} 1}-\Delta \mathrm{t}_{1}$

$\Delta t_{1}=$ equivalent time for the vehicle length of $A V_{1}$.

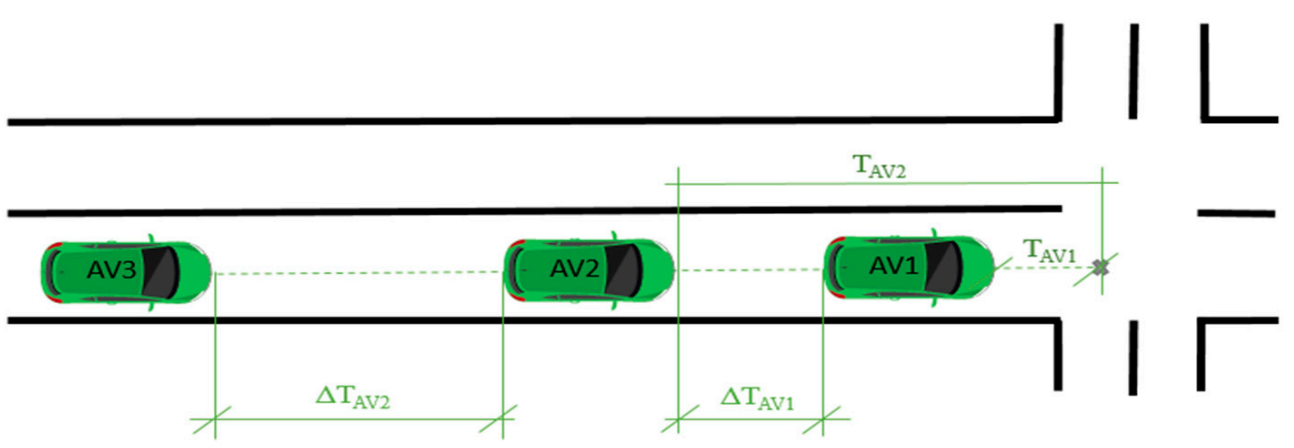

Figure 3. Desired spacing for the following vehicles.

The desired speed equation has taken into consideration the safety clearance between vehicles. It would be applied recursively for an entire vehicle fleet if they met the condition mentioned above, by using the generalized application:

If $\Delta \mathrm{T}_{\mathrm{AVi}}<\mathrm{DT}_{\mathrm{i}}+\Delta \mathrm{t}_{\mathrm{i}}$

Then denote the front $\mathrm{AV}$ that has to slow down as $\mathrm{AV}_{\mathrm{i}}$ and the immediately following vehicle as $\mathrm{AV}_{(\mathrm{i}+1)}$

The desired speed for $\mathrm{AV}_{(\mathrm{i}+1)}$ :

$$
\mathrm{V}_{\mathrm{AV}(\mathrm{i}+1)}=\frac{\mathrm{D}_{(\mathrm{i}+1)}}{\mathrm{T}_{\mathrm{AV}(\mathrm{i}+1)}+\Delta \mathrm{T}_{\mathrm{AVi}}+\Delta \mathrm{t}_{\mathrm{i}}}
$$

We implemented Equation (7) in the simulation and testing and found that the algorithm is able to effectively control the speed of a vehicle fleet, as exemplified by a few cases where the reduced speed had dropped to below $10 \mathrm{mph}$ in order to yield to the conflict vehicles.

\subsubsection{Case (I) AV/AV Payoff Matrix}

According to the above algorithm, a payoff table can be created to determine the delay time for $\mathrm{AV}_{1}$ and $\mathrm{AV}_{2}$ in all possible scenarios. For the possible vehicle movements-going through (GT), turning right (TR) or turning left (TL) - if the two vehicles are turning right or if they arrive at the intersection sequentially with a large-enough time gap, there is no conflict and the delay time will be zero for both vehicles. In the five other scenarios conflicts are possible depending on the trajectories and timing of the two vehicles when they reach the specific conflict point, as shown in Table 1. 
Table 1. Case (I) AV/AV payoff matrix for two autonomous vehicles.

\begin{tabular}{|c|c|c|c|c|}
\hline & & Autonor & s Vehicle on Eastb & d $\left(\mathrm{AV}_{2}\right)$ \\
\hline \multirow{10}{*}{$\begin{array}{l}\text { Autonomous Vehicle on } \\
\text { Southbound }\left(\mathrm{AV}_{1}\right)\end{array}$} & Strategies & TR & GT & $\mathrm{TL}$ \\
\hline & TR & $(0,0)$ & $(0,0)$ & $(0,0)$ \\
\hline & \multirow{4}{*}{ GT } & \multicolumn{3}{|c|}{ If $\mathrm{T}_{1}<\mathrm{T}_{2}-\Delta \mathrm{t}$ OR $\mathrm{T}_{1}>\mathrm{T}_{2}+\Delta \mathrm{t}$} \\
\hline & & $(0,0)$ & $(0,0)$ & $(0,0)$ \\
\hline & & \multicolumn{3}{|c|}{ If $\mathrm{T}_{1}>\mathrm{T}_{2}-\Delta \mathrm{t} \mathrm{AND} \mathrm{T}_{1}<\mathrm{T}_{2}+\Delta \mathrm{t}$} \\
\hline & & $\left(\mathrm{T}_{1}-\mathrm{T}_{2}+\Delta \mathrm{t}, 0\right)$ & $\left(\mathrm{T}_{1}-\mathrm{T}_{2}+\Delta \mathrm{t}, 0\right)$ & $\left(\mathrm{T}_{1}-\mathrm{T}_{2}+\Delta \mathrm{t}, 0\right)$ \\
\hline & \multirow{4}{*}{ TL } & \multicolumn{3}{|c|}{ If $\mathrm{T}_{1}<\mathrm{T}_{2}-\Delta \mathrm{t}$ OR $\mathrm{T}_{1}>\mathrm{T}_{2}+\Delta \mathrm{t}$} \\
\hline & & $(0,0)$ & $(0,0)$ & $(0,0)$ \\
\hline & & \multicolumn{3}{|c|}{ If $\mathrm{T}_{1}>\mathrm{T}_{2}-\Delta \mathrm{t}$ AND $\mathrm{T}_{1}<\mathrm{T}_{2}+\Delta \mathrm{t}$} \\
\hline & & $(0,0)$ & $\left(\mathrm{T}_{1}-\mathrm{T}_{2}+\Delta \mathrm{t}, 0\right)$ & $\left(\mathrm{T}_{1}-\mathrm{T}_{2}+\Delta \mathrm{t}, 0\right)$ \\
\hline
\end{tabular}

For example, if both vehicles are going through, there will be two possible situations. The first is when one of the vehicles can pass before the other arrives with no change in speed for both vehicles, and the other is when conflict is possible so there will be delay for $\mathrm{AV}_{1}$.

The delay time varies by the type of trajectory and it also varies from one vehicle to another, because $T_{1}$ and $T_{2}$ change in real time and so does $\Delta t$ according to the speed and dimensions of each vehicle.

The above payoff table shows the delay for each vehicle as a result of cooperative decision making. In the parenthesis the first number or expression represents the delay by $\mathrm{AV}_{1}$ and the second number by $\mathrm{AV}_{2}$. For simplicity to demonstrate the decision strategies and delay calculations, only one vehicle from each approach is included in the table, so there is no delay for the vehicles in most of the scenarios. The more complex case including multiple vehicles is discussed in the next section.

\subsection{Case Study (II) AV/OV in Designated Directions}

Since the AV technology is still in the development and testing stage, there will be a long period of time from now to the time of full vehicle automation (or level L5 automation according to the Society of Automotive Engineers). Therefore, it is anticipated that for the most part of next twenty to thirty years, safe and efficient operation of a mixed flow of AVs and OVs would remain a major challenge for transportation system managers. During the transition time, it is expected that designated routes for autonomous vehicles may be used since $\mathrm{AVs}$ require the roadway infrastructure be instrumented with dedicated short-range communications (DSRC) or 5G, RSU, additional video and other surveillance devices, etc. Thus, the idea of restricted roads for AVs becomes logically accepted. Moreover, the idea of AVs driving side-by-side with OVs operated by human drivers in urban areas could face additional challenges to address. Human drivers might take advantage of AVs in car-following, lane changing and stopping once they know that AVs will not run into them. On the other hand, since OVs do not communicate with the RSU it is difficult to anticipate their behavior and jointly operate the mixed flow for congestion mitigation. This problem is more realistic on urban streets and intersections, unlike on highways where access control and multidirectional lanes have simplified many vehicle maneuvers such as turning, starting up and stopping for signals.

Hence, in this study a scenario is considered where separate approaches to an intersection for AVs and $\mathrm{OVs}$ are used Figure 4. This restricted AV route intersects with a non-AV route, before it eventually connects to a highway to possibly join with other types of vehicles. 


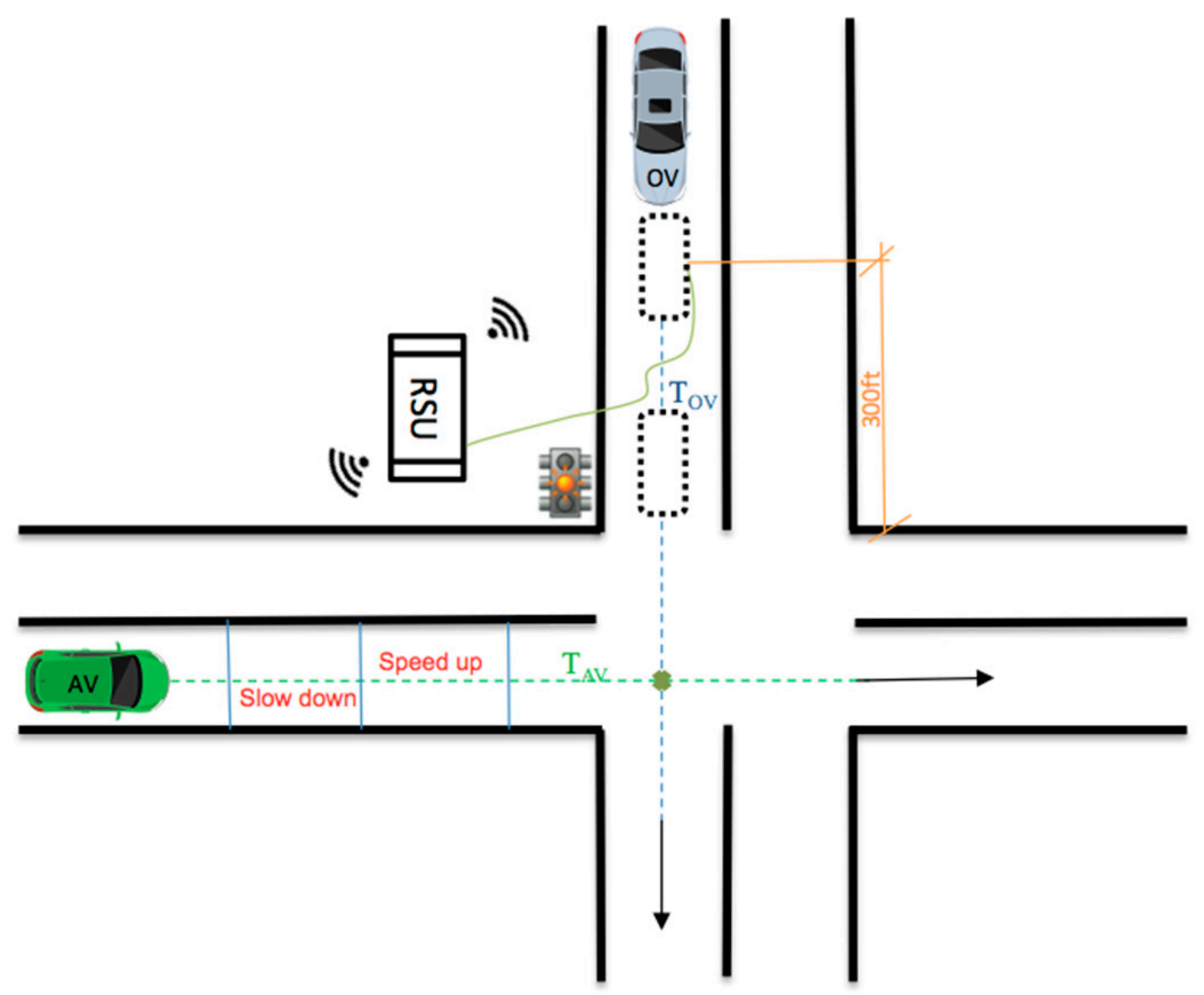

Figure 4. Case (II) AV/OV intersection illustration. OV, ordinary vehicle.

Since an OV does not automatically communicate with the RSU, separate vehicle sensors (e.g., roadway detectors) are used to find the speed of the approaching OV and its distance to the intersection. For simplicity of developing the fundamental algorithm, we consider only one-way traffic on the southbound and eastbound lane and there are no turning movements. The sensors will detect the vehicle arrivals and the data are shared with RSU to determine the conflict point between the AV and $\mathrm{OV}$. If the $\mathrm{OV}$ can safely pass the intersection before the $\mathrm{AV}$ arrives or vice versa, there will be no conflict; otherwise, the AV needs to adjust its speed since the OV should be given the priority to enhance safety and reduce delay.

The vehicle detectors on the southbound approach are placed in strategic places to provide timely data. For example, an upstream detector is placed approximately $300 \mathrm{ft}$ away from the intersection. This distance is determined following a trial and error process in the simulation and testing study for a range of posted speed limit. Furthermore, since the behavior of human drivers may be unpredictable [37], there is a chance that the driver changes speed after passing the upstream detector. Thus, another detector is placed $50 \mathrm{ft}$ away from the intersection to monitor the possible speed change of the OV and help decide if there is a need for the AV to enact the emergency braking with time requirement, $\Delta \mathrm{t}$, defined in Equation (5).

If an $\mathrm{AV}$ and an $\mathrm{OV}$ are approaching the intersection at the same time, the $\mathrm{AV}$ has two strategies: either speed up or slow down. If the AV is closer to the intersection than the $\mathrm{OV}$, then the $\mathrm{AV}$ may be able to speed up to pass the conflict point before the OV. Similarly, if the OV is closer to the intersection than $\mathrm{AV}$, then $\mathrm{AV}$ can slow down to let the OV pass the conflict point safely. The availability for the AV to speed up is cautiously checked to see if the current spacing allows for the speedup and if the resultant time gain would be adequate to utilize under a preset maximum allowable speed limit for 
the roadway. Similar to the AV/AV case discussed above, the combination of vehicle arrival times is also classified into time zones and, in this case, there are four of them. The first type is when the AV can pass the conflict point before OV arrives without changing its speed; the second type is when the $\mathrm{AV}$ can pass the conflict point after the OV has passed the point without delay; the third and fourth types of time zone are between the above two types, in which conflict is possible, and the AV has to adjust its speed to slow down in type three or speed up in type four (if the time gain is safe and usable). The details are explained below in reference to Figure 4:

- If $\mathrm{T}_{\mathrm{OV}}>\mathrm{T}_{\mathrm{AV}}+(\Delta \mathrm{t})$, the $\mathrm{AV}$ passes the conflict point before the $\mathrm{OV}$ arrives. The delay time for both vehicles is zero.

- If $\mathrm{T}_{\mathrm{OV}}<\mathrm{T}_{\mathrm{AV}}-(\Delta \mathrm{t})$, the $\mathrm{OV}$ passes the conflict point before the AV arrives. The delay time for both vehicles is zero.

- If $\mathrm{T}_{\mathrm{OV}}>\mathrm{T}_{\mathrm{AV}}-(\Delta \mathrm{t})$, the $\mathrm{AV}$ will slow down to allow the $\mathrm{OV}$ to proceed through freely. The delay time for the $\mathrm{AV}$ is $\left[\mathrm{T}_{\mathrm{OV}}-\mathrm{T}_{\mathrm{AV}}+(\Delta \mathrm{t})\right]$ and zero for the $\mathrm{OV}$.

- If $\mathrm{T}_{\mathrm{OV}}<\mathrm{T}_{\mathrm{AV}}+(\Delta \mathrm{t}$ ), the $\mathrm{AV}$ will speed up (if supported by other conditions) to pass the intersection and the $\mathrm{OV}$ is not affected to proceed through. The saved time for $\mathrm{AV}$ is $\left[\mathrm{T}_{\mathrm{OV}}-\mathrm{T}_{\mathrm{AV}}-(\Delta \mathrm{t})\right]$ and the delay time is zero for the OV.

The decision-making algorithm will be applied recursively to vehicles approaching the intersection. If the slowdown of an AV may affect the speed of other AVs behind, Equation (7) is used to manage their speed accordingly.

\section{Case (II) AV/OV Payoff Matrix}

Since priority is given to the $\mathrm{OV}$, the mixed case of $\mathrm{AV} / \mathrm{OV}$ requires strict safety measures in response to the possible status change of the OV due to the human driver, including sudden acceleration, deceleration or stopping. It should be noted again that for safety control our safety rule ensures, at any time, the time-to-collision between the AV and OV satisfy the safety time requirement, $\Delta \mathrm{t}$. We assume that the onboard sensors in the AV are able to detect an emergency and the automated system can react to it even after the OV has passed the last detector and entered the intersection. Specifically, in our modeling the safety time is constantly checked and if it is not satisfied at any moment, the speed of $\mathrm{AV}$ is reduced to maintain $\Delta \mathrm{t}$.

We have implemented the AV/OV model to process multiple vehicle arrivals. The algorithm is applied recursively for any approaching vehicle and the delay time is accumulated. Since the payoff table is very complex to describe the combinations with multiple vehicle arrivals, we have included an example (considering two vehicles from each direction) to show the decision strategies and the corresponding delay times, as shown in Table 2. In the parenthesis, the first and second number/expression represents the delay time (or saved time if negative) for the OV and the AV, respectively. Abbreviations are used in the table for clarity and to save space. Each abbreviation is explained at the end of the table. 
Table 2. Case (II) AV/OV payoff matrix.

\begin{tabular}{|c|c|c|c|c|}
\hline & & \multicolumn{3}{|c|}{$\mathbf{A V}$} \\
\hline & Strategies & Cases & Slow Down & Speed Up \\
\hline \multirow{12}{*}{ OV } & \multirow{4}{*}{ No Action } & $1 \mathrm{AV} \& 1 \mathrm{OV}$ & (0, D.T.) & (0, S.T.) \\
\hline & & $1 \mathrm{AV} \& 2 \mathrm{OVs}$ & $(0$, D.T. $+(\mathrm{W}-$ S.T. $))$ & \\
\hline & & $2 \mathrm{AVs} \& 2 \mathrm{OVs}$ & $\begin{array}{l}\text { 1st AV (0, D.T. + (W - S.T. })) \\
\left.\text { 2nd AV (0, D.T. + (W - S.T. })-\Delta t_{A V}\right)\end{array}$ & \\
\hline & & $2 \mathrm{AVs} \& 1 \mathrm{OV}$ & $\begin{array}{l}\text { 1st AV (0, D.T. }) \\
\text { 2nd AV }\left(0, \text { D.T. }-\Delta t_{A V}\right)\end{array}$ & $\begin{array}{l}\text { 2nd AV (0, S.T.) } \\
\text { 1st AV }\left(0, \text { S.T. }-\Delta t_{A V}\right)\end{array}$ \\
\hline & \multirow{4}{*}{ Speed Up } & $1 \mathrm{AV} \& 1 \mathrm{OV}$ & $\left(\left(\mathrm{T}_{\mathrm{OV} c}-\mathrm{T}_{\mathrm{OV}}\right)^{\prime}, \mathrm{D} . \mathrm{T}.\right)$ & $\left(\left(\mathrm{T}_{\mathrm{OV} c}-\mathrm{T}_{\mathrm{OV}^{\prime}}\right), \mathrm{D} . \mathrm{T}.\right)$ \\
\hline & & $1 \mathrm{AV} \& 2 \mathrm{OVs}$ & $\left(\left(\mathrm{T}_{\mathrm{OV} c}-\mathrm{T}_{\mathrm{OV}^{\prime}}\right), \mathrm{D} . \mathrm{T} .+(\mathrm{W}-\mathrm{S} . \mathrm{T}).\right)$ & $\left(\left(\mathrm{T}_{\mathrm{OV} c}-\mathrm{T}_{\mathrm{OV}^{\prime}}\right), \mathrm{D} . \mathrm{T} .+(\mathrm{W}-\mathrm{S} . \mathrm{T}).\right)$ \\
\hline & & $2 \mathrm{AVs} \& 2 \mathrm{OVs}$ & $\begin{array}{l}\text { 1st AV }\left(\left(\mathrm{T}_{\mathrm{OV} c}-\mathrm{T}_{\mathrm{OV}^{\prime}}\right), \text { D.T. }+(\mathrm{W}-\mathrm{S} . \mathrm{T} .)\right) \\
\text { 2nd AV }\left(\left(\mathrm{T}_{\mathrm{OV}}-\mathrm{T}_{\mathrm{OV}^{\prime}}\right), \text { D.T. }+(\mathrm{W}-\right. \\
\left.\text { S.T. })-\Delta \mathrm{t}_{\mathrm{AV}}\right)\end{array}$ & $\begin{array}{l}\text { 1st AV }\left(\left(\mathrm{T}_{\mathrm{OV}_{\mathrm{c}}}-\mathrm{T}_{\mathrm{OV}^{\prime}}\right), \text { D.T. }+(\mathrm{W}-\mathrm{S} . \mathrm{T} .)\right) \\
\text { 2nd AV }\left(\left(\mathrm{T}_{\mathrm{OV} \mathrm{c}}-\mathrm{T}_{\mathrm{OV}^{\prime}}\right), \text { D.T. }+(\mathrm{W}-\right. \\
\left.\text { S.T. })-\Delta \mathrm{t}_{\mathrm{AV}}\right)\end{array}$ \\
\hline & & $2 \mathrm{AVs} \& 1 \mathrm{OV}$ & $\begin{array}{l}\text { 1st } A V\left(\left(T_{O_{c}}-T_{O V^{\prime}}\right), \text { D.T. }\right) \\
\text { 2nd AV }\left(\left(T_{O V_{c}}-T_{O V^{\prime}}\right), \text { D.T. }-\Delta t_{A V}\right)\end{array}$ & $\begin{array}{l}\text { 1st AV }\left(\left(\mathrm{T}_{\mathrm{OV}_{c}}-\mathrm{T}_{\mathrm{OV}^{\prime}}\right), \mathrm{D} . \mathrm{T} .\right) \\
\text { 2nd AV }\left(\left(\mathrm{T}_{\mathrm{OV} c}-\mathrm{T}_{\mathrm{OV}^{\prime}}\right), \mathrm{D} . \mathrm{T} .-\Delta \mathrm{t}_{\mathrm{AV}}\right)\end{array}$ \\
\hline & \multirow{4}{*}{ Slow Down } & $1 \mathrm{AV} \& 1 \mathrm{OV}$ & $\left(\left(\mathrm{T}_{\mathrm{OV} c}-\mathrm{T}_{\mathrm{OV}^{\prime}}\right), \mathrm{D} . \mathrm{T}.\right)$ & $\left(\left(\mathrm{T}_{\mathrm{OV} \mathrm{c}}-\mathrm{T}_{\mathrm{OV}^{\prime}}\right), \mathrm{S} . \mathrm{T}.\right)$ \\
\hline & & $1 \mathrm{AV} \& 2 \mathrm{OVs}$ & $\left(\left(\mathrm{T}_{\mathrm{OV} c}-\mathrm{T}_{\mathrm{OV}^{\prime}}\right)\right.$, D.T. $\left.+(\mathrm{W}-\mathrm{S} . \mathrm{T}).\right)$ & \\
\hline & & $2 \mathrm{AVs} \& 2 \mathrm{OVs}$ & $\begin{array}{l}\text { 1st AV }\left(\left(\mathrm{T}_{\mathrm{OV} c}-\mathrm{T}_{\mathrm{OV}^{\prime}}\right), \text { D.T. }+(\mathrm{W}-\mathrm{S} . \mathrm{T} .)\right) \\
\text { 2nd } \mathrm{AV}\left(\left(\mathrm{T}_{\mathrm{OV} c}-\mathrm{T}_{\mathrm{OV}^{\prime}}\right), \text { D.T. }+(\mathrm{W}-\right. \\
\left.\text { S.T. })-\Delta \mathrm{t}_{\mathrm{AV}}\right)\end{array}$ & \\
\hline & & $2 \mathrm{AVs} \& 1 \mathrm{OV}$ & $\begin{array}{l}\text { 1st } A V\left(\left(\mathrm{~T}_{\mathrm{OVc}}-\mathrm{T}_{\mathrm{OV}^{\prime}}\right), \mathrm{D} . \mathrm{T} .\right) \\
\text { 2nd AV }\left(\left(\mathrm{T}_{\mathrm{OV} \mathrm{C}}-\mathrm{T}_{\mathrm{OV}^{\prime}}\right), \text { D.T. }-\Delta \mathrm{t}_{\mathrm{AV}}\right)\end{array}$ & $\begin{array}{l}\text { 2nd AV }\left(\left(\mathrm{T}_{\mathrm{OV} c}-\mathrm{T}_{\mathrm{OV}^{\prime}}\right), \text { S.T. }\right) \\
\text { 1st AV }\left(\left(\mathrm{T}_{\mathrm{OV} \mathrm{C}}-\mathrm{T}_{\mathrm{OV}^{\prime}}\right), \text { S.T. }-\Delta \mathrm{t}_{\mathrm{AV}}\right)\end{array}$ \\
\hline
\end{tabular}

where,

D.T. Delay time; calculated by $\left(\mathrm{T}_{\mathrm{OV}}-\mathrm{T}_{\mathrm{AV}}\right)+\Delta \mathrm{t}$

S.T. Saved time; calculated by $\left(\mathrm{T}_{\mathrm{OV}}-\mathrm{T}_{\mathrm{AV}}\right)-\Delta \mathrm{t}$

$\mathrm{W}$. Time to cover the entire speedup and slowdown zone for the AV.

$\Delta \mathrm{t}_{\mathrm{AV}}$ Time between the two AVs.

$\mathrm{T}_{\mathrm{OV}}$ ' Time for the $\mathrm{OV}$ to reach the conflict point, if there is no speed change.

$\mathrm{T}_{\mathrm{OV} \mathrm{c}}$ Time for the OV to reach the conflict point if there is a speed change.

A flowchart is created in Figure 5 to demonstrate the decision logic of the presented models, where the right-hand side of it deals with the decision to increase the speed [38]. For example, when a conflict AV is detected in the speed up time zone the first thing to check is if it would lead to over speeding. If yes, the AV will have to reverse its action to slow down; otherwise, it will check if there is enough distance for the AV to speed up. If no, this will lead to another checking to see if the front $\mathrm{AV}$ can speed up to give the vehicle behind room to speed up. If not, then the action will be to slow down; if yes, then both AVs would speed up together.

The left-hand side of the flowchart handles the decelerating decisions of the system. For example, when an AV needs to decelerate the system will first check if there is enough distance between this vehicle and the vehicle behind it to avoid sudden braking. If there is not enough distance for the AV to slow down, then the following AV needs to slow down too according to Equation (7). This logic flowchart is then converted to include mathematical symbols so that the system (in our case the simulation software) can read and apply it, as shown in Figure 6. 


\section{AV/OV Decision Making}

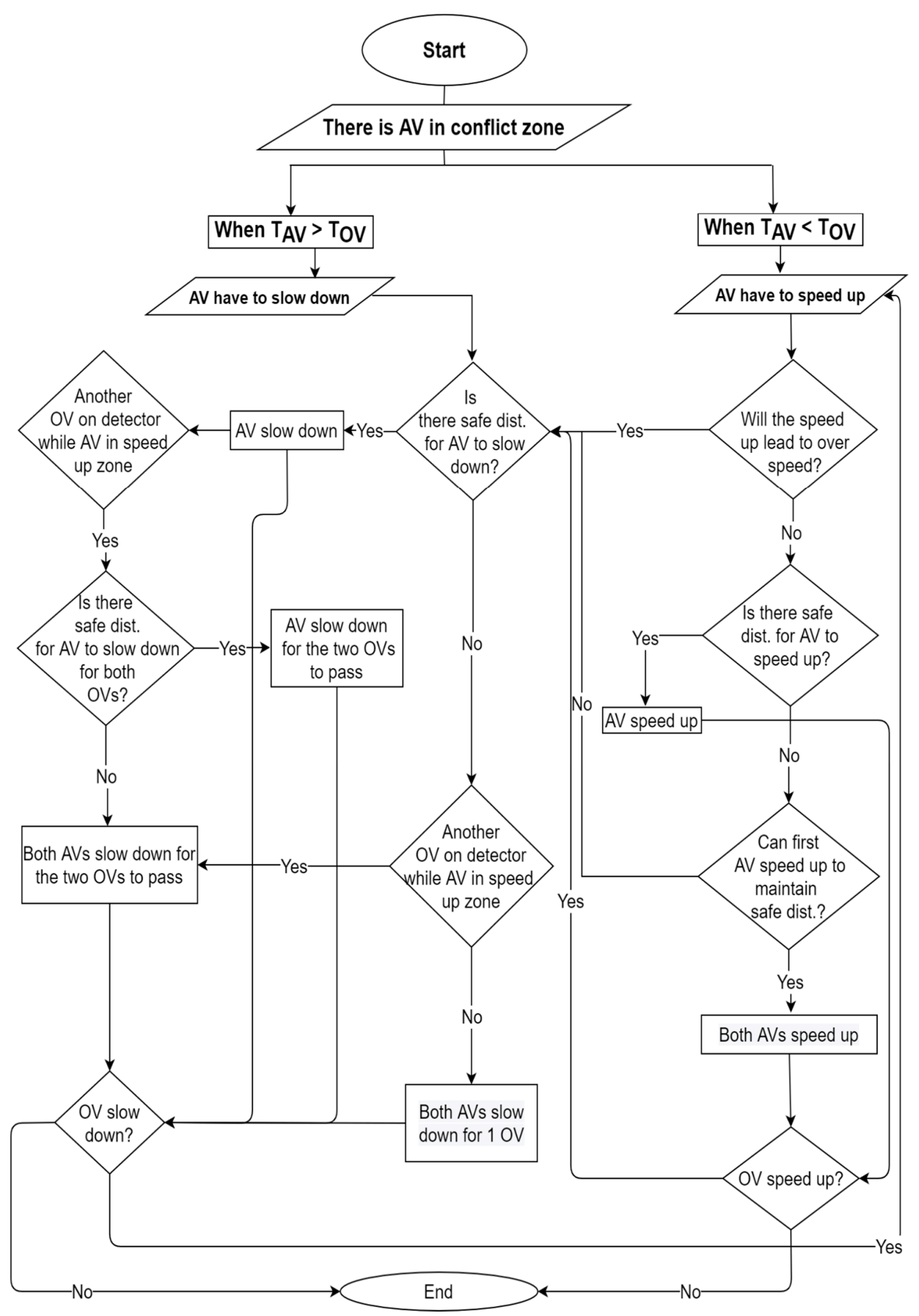

Figure 5. Case (II) AV/OV decision-making flowchart. 


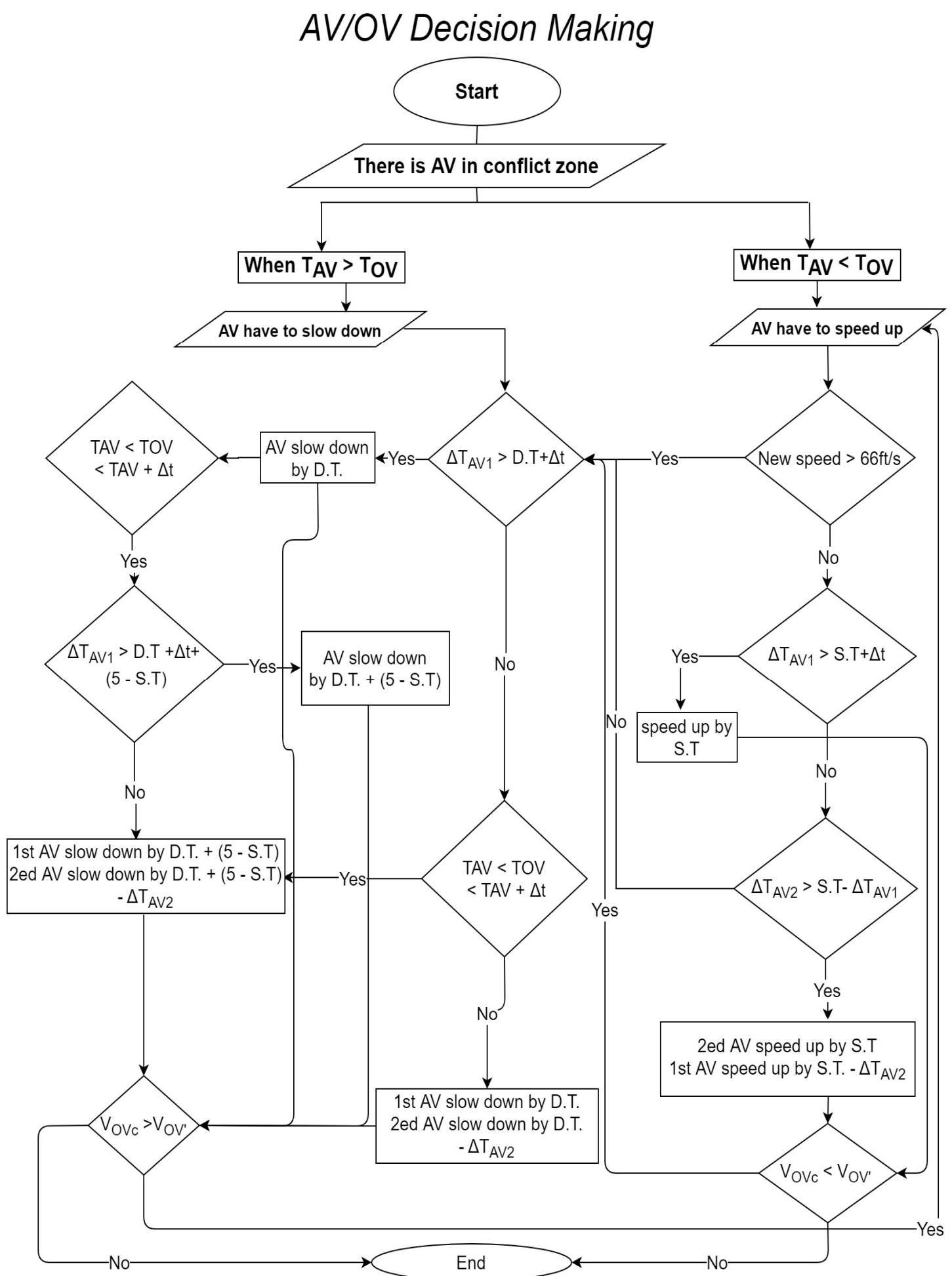

D.T.: Waiting time, $S$.T.: Saving time, $\mathrm{T}_{\mathrm{AV}} \& \mathrm{~T}_{\mathrm{OV}}$ : Time between vehicle and conflict point, $\Delta \mathrm{t}$ : min safe time between two veh., $\Delta \mathrm{T}_{\mathrm{AV} 1}$ : Time between $A V_{1}$ and $A V_{2}, \Delta \mathrm{T}_{\mathrm{AV} 2}$ : Time between $A V_{2}$ and $A V_{3}, T_{\mathrm{OV}}$ : Time at first decision, $\mathrm{V}_{\mathrm{OV}}$ : Expected OV speed in a certain distance, $T_{\text {OVc }}$ : Actual OV speed

Figure 6. Case (II) AV/OV decision-making mathematical flowchart. 


\section{Simulation, Testing, and Results}

To demonstrate the feasibility of the proposed algorithm, simulation is used to implement the priority control logic. The simulation was performed on a VISSIM platform [39] with a user interface we created to execute the algorithm. Each simulation lasts for fifteen minutes (900 s) for the AV/AV Case (I) and AV/OV Case (II). A comparison analysis between the proposed method and other current methods of intersection control was performed to show the effectiveness, including a roundabout and a four-legged signalized intersection. The simulation test performed for each method involves three different volumes [40], $750 \mathrm{vph}, 550 \mathrm{vph}$ and $250 \mathrm{vph}$, and three different speeds, $25 \mathrm{mph}, 35 \mathrm{mph}$ and $45 \mathrm{mph}$. A total of twenty-seven tests were performed for each of the two cases, in which each volume speed combination was performed three times to obtain an average for presentation.

\subsection{Case (I) AV/AV Results}

The node evaluation method in the VISSIM simulation tool was used. It works by selecting an area on the road that needs to be evaluated and then select the proper attributes of the data as output. The most critical data that we have focused on is the total delay, as shown in Table 3.

Table 3. Case (I) AV/AV total delay (sec.).

\begin{tabular}{ccccc}
\hline & & \multicolumn{3}{c}{ Speed } \\
\cline { 3 - 5 } & & $\mathbf{2 5} \mathbf{~} \mathbf{p h}$ & $\mathbf{3 5} \mathbf{~} \mathbf{p h}$ & $\mathbf{4 5} \mathbf{~} \mathbf{p h}$ \\
\hline \multirow{3}{*}{ Volume } & $250 \mathbf{v p h}$ & 5.37 & 6.48 & 1.54 \\
& $500 \mathbf{v p h}$ & 9.84 & 13.39 & 1.67 \\
& $750 \mathbf{v p h}$ & 18.77 & 21.39 & 8.61 \\
\hline
\end{tabular}

We can see from Table 3 that the total delay time is increased due to the increase of volume with all three speeds. It is interesting to notice that an increase in approaching speed does not always reduce the delay.

A simulation at a roundabout and a four-legged signalized intersection was also performed, respectively, using the same volume and speed variations to compare the delay results. Selection of these two methods is because they are currently the more common methods for intersection control. The roundabout includes four legs and each leg is controlled by a yield sign. The four-legged intersection includes one lane in each direction with a two-phase signal control, and the signal timing is obtained from the Synchro software (Trafficware, Sugar Land, TX, USA). Nine volume speed combinations for each control method were performed and each combination was repeated three times as before. The results are shown in Figure 7.

From Figure 7, we can see that there is a significant reduction in the total delay when comparing the AV/AV model with the roundabout and signalized intersection for all the speeds and volume combination. The results indicate that the roundabout creates less delay than the signalized intersection although a rigorous signal optimization effort was not made for the four-legged intersection. Nevertheless, the results are sufficient to show the advantage of AV/AV model without signal control.

From Figure 8, we can see that the total delay time is increased by the increase of volume with all three speeds, unlike the speed where the delay is not necessarily increased by the increase in speed. 


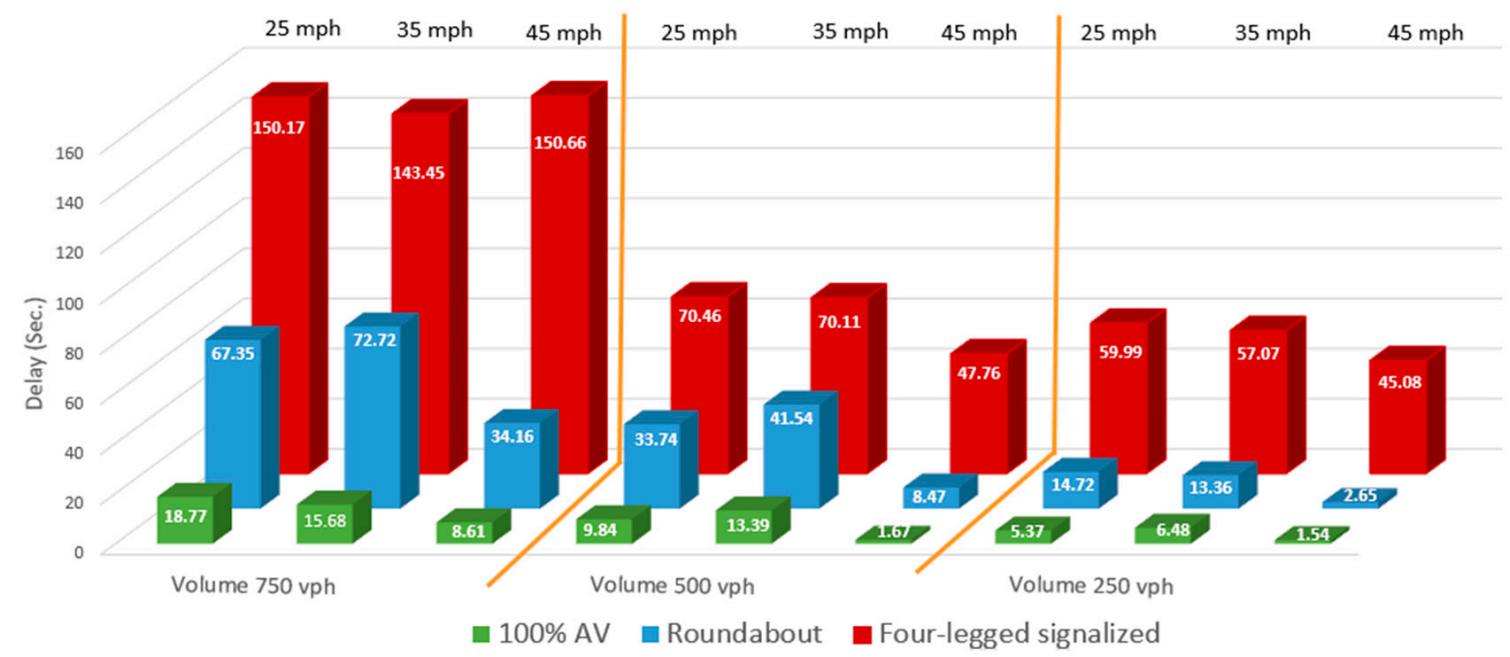

Figure 7. Case (I) AV/AV delay comparison for different types of traffic control.

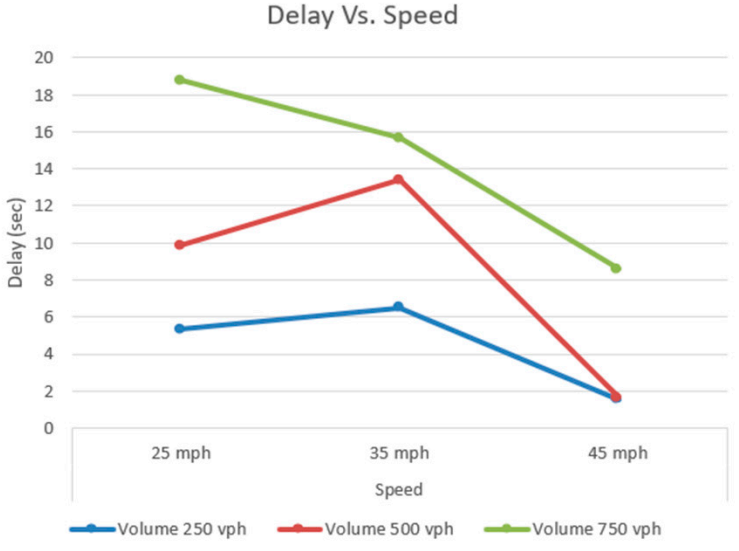

(a)

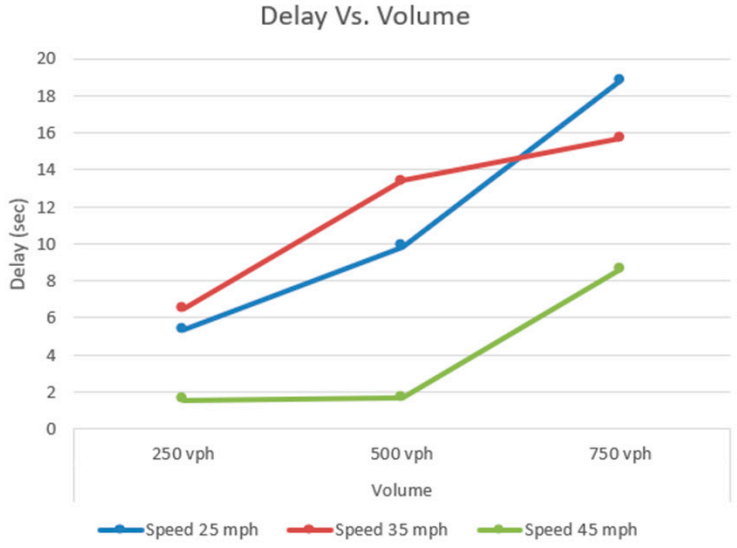

(b)

Figure 8. Case (I) AV/AV: (a) delay versus speed (b) delay versus volume.

\subsection{Case (II) $A V / O V$ Results}

In Case (II), the same number of tests as in Case (I) were performed for the same speed and volume combinations. The major difference in the simulation from Case (I) is that AVs are included only on one road and the OVs are on the other road and they are equally split at the same volume level.

From Table 4, we can see that the mixed AV and OV traffic is more difficult to handle as the traffic volume becomes heavy but the delay is generally smaller at low volumes. In some cases, there is a negative delay time. This is because of the speedup option for the AVs, which means that in this particular $15 \mathrm{~min}$ the total gain from the vehicles' speedup is more than the loss due to vehicle slowdown. In other words, there is time saved in the entire process.

Table 4. Case (II) AV/OV total delay (sec.).

\begin{tabular}{ccccc}
\hline & & \multicolumn{3}{c}{ Speed } \\
\cline { 3 - 5 } & & $\mathbf{2 5} \mathbf{~} \mathbf{p h}$ & $\mathbf{3 5} \mathbf{~} \mathbf{p h}$ & $\mathbf{4 5} \mathbf{~} \mathbf{p h}$ \\
\hline \multirow{3}{*}{ Volume } & $250 \mathrm{vph}$ & -2.93 & 6.03 & -2.47 \\
& $500 \mathrm{vph}$ & 0.96 & 13.54 & 0.03 \\
& $750 \mathrm{vph}$ & 89.32 & 11.49 & 21.88 \\
\hline
\end{tabular}


Similarly, simulation at a roundabout and a four-legged signalized intersection was also made to compare the delays and the effectiveness when there is no turning movement at the intersection as shown in Figure 4. In this case, the origin destination (O-D) demand for the roundabout and the four-legged intersection is changed as all vehicles are made to go through the intersection without turning. Similarly, nine test combinations for each control method were performed to compare the results for all speeds and volume levels. The results are shown in Figure 9.

As shown in Figure 9, there is a significant reduction in the total delay time comparing with roundabout and signalized intersection for all speeds and volume as the bar chart shows. The results indicate that a roundabout creates less delay than a signalized intersection, which makes sense because traffic lights force vehicles to a complete stop, not like a roundabout where vehicles only yield for vehicles that are already on the roundabout, and in case (II), the intersection can be managed by slowing down and speeding up. That would explain the progression in the delay from high to low. Although delay is increased for the AV/OV scenario at a volume level of $750 \mathrm{vph}$ due to the presence of OVs, the advantage of the AV/OV model is shown clearly in Figure 9, where a large difference in delay is shown when compared with the roundabout and signalized intersection control. At lower volume levels, the AV/OV model has demonstrated its ability to reduce delay from the use of speedup options for AVs.

From the Figure 10b, we can see that the total delay time is increased by the increase of volume with all three speeds, unlike the speed Figure 10a where the delay is not necessarily increased by the increase in speed. Another point that can be seen in the charts that the delay with $750 \mathrm{vph}$ volume is relatively high compared with other volumes. Also, there is some negative value of delay, which results from the speed up option. It means that in the total simulation time (900 s), vehicles actually save time rather than waste time.

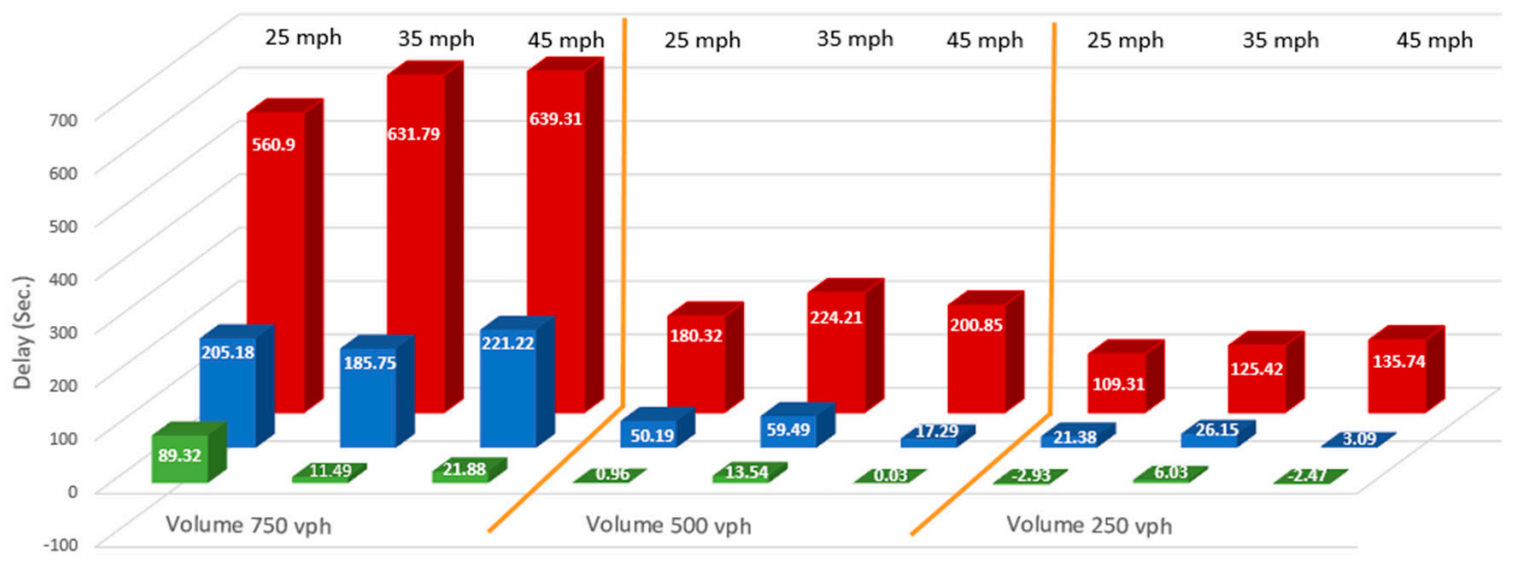

घ Mixed AV + OV घ Roundabout $\mathbf{a}$ Four-legged signalized

Figure 9. Case (II) AV/OV Delay comparison for different types of traffic control. 


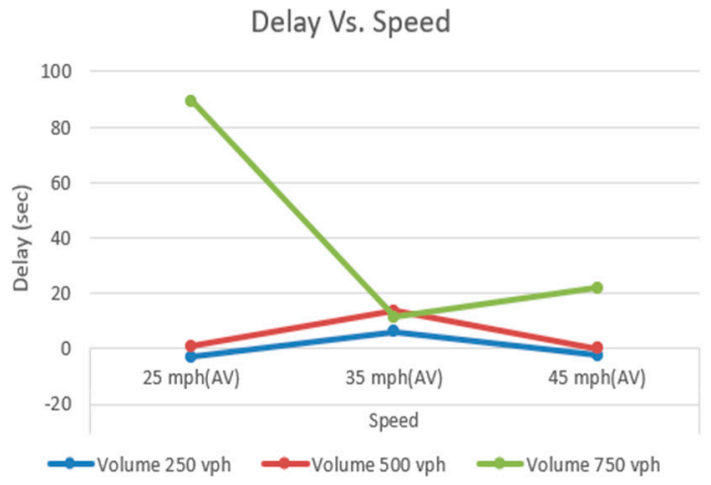

(a)

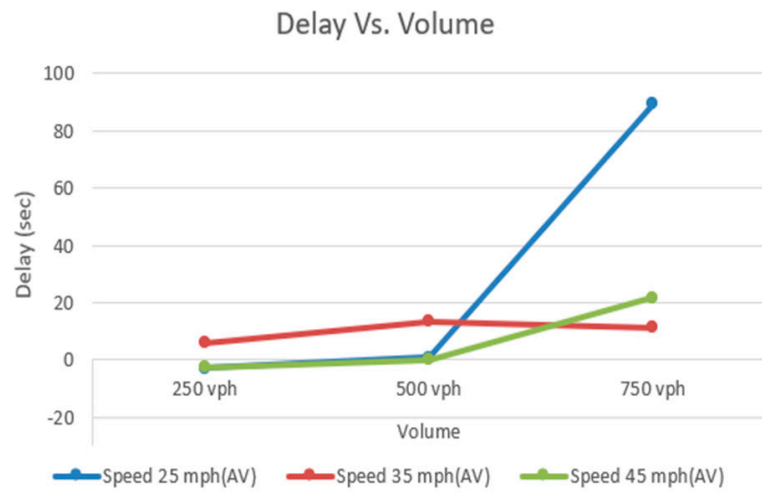

(b)

Figure 10. Case (II) AV/OV: (a) delay versus speed (b) delay versus volume.

\section{Conclusions}

This research has developed a priority control algorithm for optimizing the movement of vehicles at intersections in the context of autonomous vehicle applications. The proposed algorithm uses game theory and trajectory-based conflict point identification to reduce the intersection delay while ensuring traffic safety. The proposed framework makes use of the V2I infrastructure for sharing data in order to control the movement of autonomous vehicles with and without the interference from the ordinary vehicles. Thenceforward, the payoff table is formed to find the best strategies for vehicles in different conditions. Two different mathematical models were developed; one with $100 \%$ autonomous vehicles and the other with a mixed traffic of autonomous vehicles and ordinary vehicles. A simulation model was created to implement the decision-making algorithm in each case. A comparison of the proposed two models was performed at different volume and speed levels, against two other commonly used intersection control methods involving a roundabout and a four-legged signalized intersection. The results show that the proposed system is able to reduce the total delay by up to $65 \%$ compared with the roundabout, and up to $90 \%$ compared with the signalized intersection.

This research represents a piece of original work, although certain assumptions are used to simplify the geometric and traffic conditions. The simulation and test results have clearly demonstrated the feasibility and advantage of autonomous vehicles as an emerging technology for safe and efficient operations in mixed traffic. Future work will include expansion of the algorithm to consider multilane and multidirection traffic, and an increase of testing scenarios to investigate the impact of autonomous vehicles at different levels of market penetration.

Author Contributions: Conceptualization, A.B. and P.Y.; methodology, A.B. and A.Q.; software, A.B.; validation, A.B., P.Y. and A.Q.; writing-original draft preparation, A.B.; writing-review and editing, P.Y. All authors have read and agreed to the published version of the manuscript.

Funding: This research was supported by: Saudi Arabian Cultural Mission to the US, Ministry of Education.

Conflicts of Interest: The authors declare no conflict of interest.

\section{References}

1. Goodall, N. Ethical Decision Making During Automated Vehicle Crashes. Transp. Res. Rec. J. Transp. Res. Board 2014, 2424, 58-65. [CrossRef]

2. Kockelman, K.; Boyles, S.; Stone, P.; Fagnant, D. An Assessment of Autonomous Vehicles: Traffic Impacts and Infrastructure Needs. Final Report (FHWA 0-6847-1). Cent. Transp. Res. Univ. Texas Austin 2016. Available online: http://library.ctr.utexas.edu/ctr (accessed on 3 December 2019).

3. NHTSA. What are the Advantages of V2V? U.S. Department of Transportation: Washington, DC, USA, 2014; pp. 1-4. 
4. Au, T.; Zhang, S.; Stone, P. Autonomous Intersection Management for Semi-Autonomous Vehicles. Handb. Transp. 2015, 88-104. [CrossRef]

5. Malikopoulos, A.A.; Cassandras, C.G. A Decentralized Optimal Control for Connected and Automated Vehicles at an Intersection. arXiv 2016, arXiv:1602.03786. Available online: http://arxiv.org/abs/1602.03786 (accessed on 21 August 2019).

6. Sun, W.; Zheng, J.; Liu, H.X. A capacity maximization scheme for intersection management with automated vehicles. Transp. Res. Procedia 2016, 23, 121-136. [CrossRef]

7. Timmerman, R.W.; Boon, M.A.A. Platoon forming algorithms for intelligent street intersections. Transportmetrica Transp. Science 2019. [CrossRef]

8. Zohdy, I.H.; Kamalanathsharma, R.K.; Rakha, H. Intersection Management for Autonomous Vehicles using iCACC. In Proceedings of the 2012 15th International IEEE Conference on Intelligent Transportation System, Anchorage, AK, USA, 16-19 September 2012; p. 6. [CrossRef]

9. Hausknecht, M.; Au, T.C.; Stone, P. Autonomous Intersection Management: Multi-Intersection Optimization. In Proceedings of the 2011 IEEE International Conference on Intelligent Robots and Systems, San Francisco, CA, USA, 25-30 September 2011; pp. 4581-4586. [CrossRef]

10. Manzini, R.; Accorsi, R.; Baruffaldi, G.; Cennerazzo, T.; Gamberi, M. Travel time models for deep-lane unit-load autonomous vehicle storage and retrieval system (AVS/RS). Int. J. Prod. Res. 2016, 7543, 1-19. [CrossRef]

11. Dresner, K.; Stone, P. Sharing the Road: Autonomous Vehicles Meet Human Drivers. In Proceedings of the 20th IJCAI International Joint Conference on Artificial Intelligence, Hyderabad, India, 6-12 January 2007; pp. 1263-1268.

12. Ahn, H.; Colombo, A.; Del Vecchio, D. Supervisory Control for Intersection Collision Avoidance in the Presence of Uncontrolled Vehicles. In Proceedings of the American Control Conference, Portland, OR, USA, 4-6 June 2014; pp. 867-873. [CrossRef]

13. Xia, X.; Ma, X.; Wang, J. Control method for signalized intersection with integrated waiting area. Appl. Sci. 2019, 9, 968. [CrossRef]

14. Debra, P.E.; Kennaugh, A. Intersection Safety A Manual for Local Rual Road Owners; FHWA-SA-11-08; U.S. Department of Transportation FHWA: Washington, DC, USA, 2006; Volume 1, pp. 1-43.

15. Macioszek, E. The Influence of Motorcycling and Cycling on Small One-Lane Roundabouts Capacity. In Proceedings of the International Conference on Transport System Telematics, Uston, Poland, 19-22 October 2011; Volume 239 CCIS, pp. 291-298. [CrossRef]

16. Bulla-Cruz, L.A.; Laureshyn, A.; Lyons, L. Event-based road safety assessment: A novel approach towards risk microsimulation in roundabouts. Measurement 2020, 165, 13. [CrossRef]

17. Bagdatli, M. Vehicle Delay Modeling at Signalized Intersections with Gene-Expression Programming. J. Transp. Res. Part A Syst. 2020, 146, 13. [CrossRef]

18. Tandelis, S. Game Theory. Ph.D. Thesis, Princeton University Press, Princeton, NJ, USA, 2013; p. xv 396.

19. Osborne, M. An Introduction to Game Theory; Oxford University Press: New York, NY, USA, 2003; p. 560.

20. Bui, K.-H.N.; Jung, J.E.; Camacho, D. Game theoretic approach on Real-time decision making for IoT-based traffic light control. Concurr. Comput. Pract. Exp. 2017, 29, e4077. [CrossRef]

21. Pantaleão, L.H.; Azevedo, M.H.; Antunes, J.A.V., Jr. Use of a non-zero-sum game as a teaching tool about organizational indicators: Optimum local X Nash equilibrium. In Proceedings of the Second World Conference on POM and 15th Annual POM Conference, Cancun, Mexico, 30 April-3 May 2004; Wiley: New York, NY, USA, 2004.

22. Arora, S. Nonzero Sum Games and Nash Equilibria; Princeton University: Princeton, NJ, USA, 2006; Volume 0, pp. 1-6.

23. Zohdy, I.; Rakha, H. Enhancing roundabout operations via vehicle connectivity. Transp. Res. Rec. $2013,2381$. [CrossRef]

24. Osborne, M.; Rubinstein, A. A Course in Game Theory. MIT 2011, 368. Available online: http://ebour.com.ar/ pdfs/ACourseinGameTheory.pdf (accessed on 26 June 2018).

25. Anonymous. 4 Bimatrix Games. pp. 27-64. Available online: http://euler.fd.cvut.cz/predmety/game_theory/ games_bim.pdf (accessed on 18 September 2017).

26. Rakha, H.A.; Zohdy, I.H.; Kamalanathsharma, R.K. Agent-Based Game Theory Modeling for Driverless Vehicles at Intersections; U.S. Department of Transportation UTC: Washington, DC, USA, 2013; Volume VT-2010-02, p. 44. 
27. Banjanovic, L.-M.; Halilovic, E.; Bosankic, I.; Kantardzic, M.; Kasapovic, S. Autonomous Vehicle-to-Vehicle (V2V) Decision Making in Roundabout using Game Theory. Int. J. Adv. Comput. Sci. Appl. 2016, 7, 292-298. [CrossRef]

28. Khoury, J.; Khoury, J. Passive, Decentralized, and Fully Autonomous Intersection Access Control. In Proceedings of the 17th IEEE International Conference on Intelligent Transportation System ITSC 2014, Qingdao, China, 8-11 October 2014; pp. 3028-3033. [CrossRef]

29. Chapter 10-Signalized Intersections: Informational Guide, August 2004, FHWA-HRT-04-091. 2004. Available online: https:/www.fhwa.dot.gov/publications/research/safety/04091/10.cfm (accessed on 19 July 2018).

30. Levin, M.W.; Rey, D. Conflict-point formulation of intersection control for autonomous vehicles. Transp. Res. Part C Emerg. Technol. 2017, 85, 528-547. [CrossRef]

31. Divion, T.; Divion, S. Traffic Sign Design, Placement, and Application Guidelines Prepared by Traffic and Safety Design Division, Michigan DoT. 2017. Available online: https://mdotcf.state.mi.us/public/tands/ Details_Web/mdot_signing_design_placement_application_guidelines.pdf (accessed on 19 July 2018).

32. Tupper, S.M. Safety and Operational Assesment of Gap Acceptance Through Large-Scale Field Evaluation. Ph.D. Thesis, University of Massachusetts Amherst, Amherst, MA, USA, May 2011.

33. Dixit, V.V.; Chand, S.; Nair, D.J. Autonomous Vehicles: Disengagements, Accidents and Reaction Times. PLoS ONE 2016, 11, e0168054. [CrossRef] [PubMed]

34. Layton, R.; Dixon, K. Stopping Sight Distance. 2012. Available online: http://cce.oregonstate.edu/sites/cce. oregonstate.edu/files/12-2-stopping-sight-distance.pdf (accessed on 18 July 2018).

35. Sena, P.; D'amore, M.; Brandimonte, M.A.; Squitieri, R.; Fiorentino, A. Experimental Framework for Simulators to Study Driver Cognitive Distraction: Brake Reaction Time in Different Levels of Arousal. Transp. Res. Procedia 2016, 14, 4410-4419. [CrossRef]

36. Reis, A.B.; Sargento, S.; Neves, F.; Tonguz, O.K. Deploying roadside units in sparse vehicular networks: What really works and what does not? IEEE Trans. Veh. Technol. 2014, 63, 2794-2806. [CrossRef]

37. Doshi, A.; Trivedi, M.M. Examining the Impact of Driving Style on the Predictability and Responsiveness of the Driver: Real-world and Simulator Analysis. In Proceedings of the 2010 IEEE Intelligent Vehicles Symposium, San Diego, CA, USA, 21-24 June 2010; Available online: http://cvrr.ucsd.edu/LISA (accessed on 19 July 2018).

38. Mayer, R.E. Models for Understanding. Rev. Educ. Res. 1989, 59, 43-64. Available online: http: //journals.sagepub.com/doi/pdf/10.3102/00346543059001043 (accessed on 19 July 2018). [CrossRef]

39. PTV Vissim. Available online: http://vision-traffic.ptvgroup.com/en-us/products/ptv-vissim/ (accessed on 9 June 2018).

40. What is the Traffic Volume Cut off between High-Volume and Low Volume? Available online: https: //www.clrp.cornell.edu/q-a/151-low-volume.html (accessed on 19 July 2018). 